\title{
Ophthalmic Manifestations of Covid-19: A Bibliometric Assessment of Global Scientific Literature
}

\author{
Kanu Chakraborty ${ }^{1, *}$, BM Gupta ${ }^{2}$, Manashree Chakraborty ${ }^{3}$, Rajpal Walke ${ }^{4}$ \\ ${ }^{1}$ Indian Institute of Technology (B.H.U.), Varanasi, Uttar Pradesh, INDIA. \\ ${ }^{2}$ CSIR-NISTADS, New Delhi, INDIA. \\ ${ }^{3}$ Apex College of Nursing, Varanasi, Uttar Pradesh, INDIA \\ ${ }^{4}$ CSIR-NPL, New Delhi, INDIA.
}

\begin{abstract}
Purpose: The Covid-19 pandemic has significantly impacted world healthcare, with ophthalmology being one of the most severely affected area. The study aims to perform a bibliometric analysis of global literature published on "Ophthalmic Manifestations of Covid-19" to explore the scientific productivity and trends in research in this field. Methods: Bibliometric methods have been used to analyze global literature on this topic using quantitatively and qualitatively indices from the Scopus database up to $20^{\text {th }}$ September 2021. The keywords related to "Covid-19" and "ophthalmology" are used in search strategy through the boolean operator. Primary data were exported in CSV and BibTxt file format for further analysis using different software. The literature on "Ophthalmic Manifestations of Covid-19" was assessed using a variety of metrics. Results: A total of 3453 publications were published on "Ophthalmic Manifestations of Covid-19", which received 32935 citations, averaging 9.54 citations per paper. Of the total publications, 557 received external funding support and registered 10802 citations. The U.S.A. and India published the most significant number of papers among countries. The U.S.A. and U.K. occupied the top position in international collaborative publications. Medicine and Neurosciences were the most productive areas. The Indian Journal of Ophthalmology is the most productive source. A total of 46
\end{abstract}

high-cited papers have been identified on this topic, which are published in 35 journals, with the U.S.A. contributing the most papers. Conclusion: In this study, the bibliometric assessment presents a quantitative and qualitative matrix of research in the field "Ophthalmic Manifestations of Covid-19". The study gives proof of the enhanced global collaboration that global researchers have created in order to combat the epidemic. The authors have used various bibliometric metrics and tools to present this study efficiently. This study will be helpful for the scholars who were researching in this field.

Key words: Covid -19, SARS-CoV-2, Ophthalmology, Global publications, Bibliometrics, Scientometrics.

Correspondence

Mr. Kanu Chakraborty,

Indian Institute of Technology (B.H.U.), Varanasi-221005, IIT-BHU, Uttar Pradesh, INDIA.

Email id: kchakraborty.lib@iitbhu.ac.in

DOI: 10.5530/jyp.2021.13s.80

\section{INTRODUCTION}

The Covid-19 virus enters the body through different organs in different ways, as established during the research world over. The impact of Covid-19 on different body organs is also increasing over time, as reflected in research output. The eye is a vital part exposed to the environment for easy transmission of the novel coronavirus. SARS-CoV-2 could use the human ocular surface as an additional entry point and infection hub. ${ }^{1}$

Since December 2019, Coronavirus disease 2019 (Covid-19) has become a global pandemic caused by the highly transmissible severe acute respiratory syndrome coronavirus 2 (SARS-CoV-2). ${ }^{2}$ Initially, there were several reports of eye redness and irritation in Covid-19 patients, both anecdotal and published, suggesting that conjunctivitis is an ocular manifestation of SARS-CoV-2 infection. Reports continue to emerge on further associations of Covid-19 with uveitic, retinovascular, and neuroophthalmic diseases. ${ }^{3}$

Early studies postulated that ocular manifestations of Covid-19 were rare. More recent data, however, have supported a much higher incidence of ocular signs and symptoms. The potential of infection through ocular secretions is currently unknown, and it remains unclear how SARSCoV-2 accumulates in ocular secretions. Possible theories include direct inoculation of the ocular tissues from respiratory droplets or aerosolized viral particles, migration from the nasopharynx via the nasolacrimal duct, or even hematogenous spread through the lacrimal gland. ${ }^{4}$ The prevalence of ocular manifestations in patients with Covid-19 ranges from $2 \%$ to $32 \% .^{5}$

Ocular manifestations of Covid-19 have most commonly presented with conjunctivitis otherwise indistinguishable from other viral etiologies. Differential diagnosis includes a broad range of common ocular manifestations of eye redness and increased tearing: (i) Other viral conjunctivitis (e.g., adenovirus), (ii) Bacterial conjunctivitis, (iii) Allergic conjunctivitis, (iv) Herpes simplex virus keratitis, (v) Anterior uveitis, (vi) Corneal abrasion, (vii) Foreign body, (viii) Dry eye syndrome, (ix) Exposure keratopathy in an intubated patient and (x) Chemosis in a critically ill patient.

Although several studies have been conducted that explore the Covid-19 effect on lungs, kidney, skin and liver, only a few bibliometric studies have been published on the effect of Covid-19 on eyes. That is why a bibliometric analysis of Covid-19 research in ophthalmology is required. This quantitative examination of the data will provide useful information for future ophthalmic research. The paper presents a bibliometric analysis of the scientific literature published globally on "Ophthalmic Manifestations of Covid-19", as covered in the Scopus database. The analysis specific objectives include overall research output of globally

This is an open access article distributed under the terms of the Creative Commons Attribution-NonCommercial-ShareAlike 4.0 License, which allows others to remix, tweak, and build upon the work non-commercially, as long as the author is credited and the new creations are licensed under the identical terms. 
ophthalmology disease complications in a patient with Covid - 19 infections in terms of most important countries, organizations, authors, journals and their collaborative interrelationship and important subject areas of focus. The Covid-19 pandemic has demonstrated the value of data and science in restoring more resilient health systems and accelerating equitable progress toward our shared global goals.

\section{Literature Review}

A few bibliometric studies on "Ophthalmic Manifestations of Covid-19" are available, but these studies have undertaken a limited analysis and are not up-to-date. Among them, Kalra, Kaur. Ichhpujani, Chahal and Kumar $^{6}$ examined 616 global publications on Covid-related research on ophthalmology involving 2308 authors from 63 sources using the Web of Science database till 22th February 2021. Different softwares were used to visualize metrics to quantify geographical distribution, source, author, document, keyword matrices. Jin, Trope, Graham, El-Defrawy, Liu and Buys ${ }^{7}$ examined Covid-19 research publications by ophthalmologists/researchers in terms of publication numbers, journals and author countries and to detail key findings. A total of 21,364 articles were registered in Lit Covid on June 12, 2020. Of these, 308 were found in the initial search for ophthalmology-focused publications. Du Reitinger., Jain. and Suh ${ }^{8}$ examined the effects of Covid-19 on ophthalmology, using publications from PubMed each month from January 2020 to August 2020. In addition, wthe authors examined new clinical trials within multiple databases (Clinicaltrials.gov, University Hospital Medical Information Network, Australian New Zealand Clinical Trials Registry, and International Standard Randomized Controlled Trial Number Registry) using the keywords "ophthalmology" or "eye diseases." Sen, Honavar, Sharma, Namrata and Sachdev ${ }^{9}$ reviewed the literature on ophthalmologic manifestation of Covid-19, usind data from I January 2020 to 31 January 2021 from different databases. The studies reviewed include 46 case reports, 8 case series, 11 cross-sectional/ cohort observational studies, 5 prospective interventional studies, 3 animal model/autopsy studies and 6 reviews and meta-analysis. Conjunctivitis is the most common manifestation and can develop at any stage of the disease. Direct effect due to virus, immune-mediated tissue damage, activation of the coagulation cascade and prothrombotic state included by the virtual infection, the associated comorbidities and drugs used in the management are responsible for the findings in the eye. Due to the present shifting landscape within medical literature and insufficient information on the topic "Ophthalmic Manifestations of Covid-19", the authors investigated the trends and implications of Covid-19 on ophthalmology. In this paper, the authors have analyzed 3453 global records, which received 32935 citations up to September $20^{\text {th }}$ 2021.

\section{METHODS AND MATERIALS}

The authors used bibliometric methods to analyze global literature on "Ophthalmic Manifestations of Covid-19" from literature indexed in the Scopus database (https://scopus.com). ${ }^{10}$ The search query used was as follows:

(TITLE ("Covid 19" or "2019 novel coronavirus" or "coronavirus 2019" or "coronavirus disease 2019" or "2019-novel CoV" or "2019 ncov" or Covid 2019 or Covid19 or "corona virus 2019" or ncov-2019 or ncov2019 or "nCoV 2019" or 2019-ncov or covid-19 or "Severe acute respiratory syndrome coronavirus 2" or "SARS-CoV-2") or KEY( "Covid 19" or "2019 novel coronavirus" or "coronavirus 2019" or "coronavirus disease 2019" or "2019-novel CoV” or "2019 ncov" OR covid 2019 or covid19 or "corona virus 2019" or ncov-2019 or ncov2019 or "nCoV 2019" OR 2019-ncov or covid-19 or "Severe acute respiratory syndrome coronavirus 2" or "SARS-CoV-2") and KEY (Eye* or optical* or ophth* or conjunct ${ }^{\star}$ or glauma ${ }^{\star}$ or visual $\left.{ }^{\star}\right)$ ).

Primary data were exported in CSV and BibTxt file format for analysis through the Bibliometrix R library (Biblioshiny app), ${ }^{11}$ Vosviewer, and Spreadsheet. The literature on "Ophthalmic Manifestations of Covid-19" was assessed using a variety of metrics, as detailed in the result and analysis section.

\section{Analysis and Results Overall Data}

In all a total of 3453 publications were retrieved from the Scopus database on "Ophthalmic Manifestations of Covid-19" during 2019 to $2022(2019=1,2020=1648,2021=1798$ and $2022=6)$. These publications have received 32935 citations, with citations per paper of 9.54. Of the 3453 publications on this theme, 557 received external funding support and received 10802 citations, averaging 19.39 citations per paper. The major funding agencies along with their output are: National Natural Science Foundation of China (98 papers), National Institutes of Health (97 papers), Research to Prevent Blindness (40 papers), U.S. Department of Health and Human Services (36 papers), National Aeronautics and Space Administration (27 papers), National Science Foundation (27 papers), European Commission (24 papers), National Key Research and Development Program of China (24 papers), Novartis (24 papers), National Institute for Health Research (23 papers).

Among document types, articles constituted the largest number (1937), followed by letters (553), reviews (437), conference papers (180), editorials (170), notes (152), short surveys (13), book chapters (10), data paper (1).

\section{Geographic distribution}

In all 117 countries participated in research on "Ophthalmic Manifestations of Covid-19": 66 countries contributed 1-10 papers each. 14 countries 11-20 papers each, 26 countries 21-100 papers each, 6 countries 108-156 papers each and 5 countries 329-818 papers each.

The top 10 countries individually published 116 to 818 papers and together accounted $85.46 \%$ share (2951 papers) and more than $100 \%$ share (37218 citations) of global publications and citations. On further analysis, it was observed that; (i) Four countries registered publications above the group average (295.1) of the top 10 countries: U.S.A. (818 papers), India (435 papers), U.K. (345 papers) and China (336 papers); and (ii) Four countries registered citation per paper and relative citation index above the top 10 countries group average (12.61 and 1.32): China (23.7 and 2.48), Canada (17.16 and 1.80), U.S.A. (14.14 and 1.48) and Italy (12.88 and 1.35). The international collaborative publications share of top 10 countries varied from $17.74 \%$ to $49.14 \%$, with an average of $32.87 \%$; and five countries registered percentage share of international collaborative publications above the group average $(32.87 \%)$ of top 10 countries: Canada (49.14\%), U.K. (47.83\%) Germany (47.62\%), France (40.69\%) and China (33.33) (Table 1).

The collaborative linkages among the top 10 countries are shown in Table 2. The highest collaborative linkages (263, 244 and 162) among the top 10 countries are made by the USA, U.K. and Italy. The individual country-to-country collaborative linkages varied from 1 to 52 . The highest country to country collaborative linkages (52) is registered by USA - U.K. and USA - China, followed by USA - Germany (27 linkages), USA - Italy (26 linkages), etc. (Table 2). The collaborative linkages between top countries are depicted in Figure 1-2.

The nodes indicate countries, and the size of the nodes reflects the frequency of collaboration publishing. The edges represent the country links, and the width of the edges reflects the frequency of node co- 
Table 1: Bibliometric Profile of Top 10 Countries.

\begin{tabular}{|c|c|c|c|c|c|c|c|}
\hline S.No & Name of the country & TP & TC & CPP & ICP & \%ICP & $\mathrm{RCl}$ \\
\hline 1 & USA & 818 & 11567 & 14.14 & 266 & 32.52 & 1.48 \\
\hline 2 & India & 435 & 2553 & 5.87 & 87 & 20.00 & 0.62 \\
\hline 4 & China & 336 & 7963 & 23.70 & 112 & 33.33 & 2.48 \\
\hline 5 & Italy & 329 & 4237 & 12.88 & 81 & 24.62 & 1.35 \\
\hline 8 & France & 145 & 1548 & 10.68 & 59 & 40.69 & 1.12 \\
\hline 9 & Turkey & 124 & 643 & 5.19 & 22 & 17.74 & 0.54 \\
\hline \multirow[t]{2}{*}{10} & Canada & 116 & 1990 & 17.16 & 57 & 49.14 & 1.80 \\
\hline & Total of 10 countries & 2951 & 37218 & 12.61 & 970 & 32.87 & 1.32 \\
\hline
\end{tabular}

TP - Total Publications, TC - Total Citations, CPP - Citations per Paper, HI - Hirsch Index, ICP - International Collaborative Publications, RCI - Relative citation impact

Table 2: The Extent of Collaborative Linkages among Top 10 Countries.

\begin{tabular}{clcc}
\hline SI.No & Name of the country & Number of collaborating linkages & Total collaborative linkages \\
\hline 1 & USA & $2(36), 3(52), 4(52), 5(26), 6(18), 7(27), 8(21), 9(7), 10(24)$ & $263(9)$ \\
2 & India & $1(36), 3(22), 4(6), 5(2), 6(4), 7(14), 8(5), 9(2), 10(3)$ & $94(9)$ \\
3 & U.K. & $1(52), 2(22), 4(24), 5(38), 6(24), 7(31), 8(28), 9(8), 10(17)$ & $244(9)$ \\
4 & China & $1(52), 2(6), 3(24), 5(11), 6(11), 7(13), 8(10), 9(7), 10(12)$ & $146(9)$ \\
5 & Italy & $1(26), 2(2), 3(38), 4(11), 6(21), 7(19), 8(22), 9(11), 10(12)$ & $162(9)$ \\
6 & Spain & $1(18), 2(4), 3(24), 4(11), 5(21), 7(17), 8(20), 9(10), 10(8)$ & $133(9)$ \\
7 & Germany & $1(27), 2(14), 3(31), 4(13), 5(19), 6(17), 8(18), 9(10), 10(11)$ & $160(9)$ \\
$8)$ & France & $1(21), 2(5), 3(28), 4(10), 5(22), 6(20), 7(18), 9(10), 10(14)$ & $148(9)$ \\
9 & Turkey & $1(7), 2(2), 3(8), 4(7), 5(11), 6(10), 7(10), 8(10), 10(6)$ & $71(9)$ \\
10 & Canada & $1(24), 2(3), 3(17), 4(12), 5(12), 6(8), 7(11), 8(14), 9(6)$ & $107(9)$ \\
\hline
\end{tabular}

occurrence. A broader edge indicates a stronger relationship or a higher co-occurrence frequency. The colour of nodes indicates which group they belong to, with nodes in the same group being more similar to each other than nodes in other groups. The Betweenness Closeness represents the close collaboration pattern among the countries. Six clusters have been shown in Figures 1-2. The U.S.A., India, UK, China and Italy show a significant collaboration pattern and bibliographic coupling.

\section{Subject Wise Distribution}

Table 3 shows the subject-wise distribution of publications on “Ophthalmic Manifestations of Covid-19”. 'Medicine' was observed to be the most productive area (with $78.95 \%$ publication share), followed by Neurosciences ( $8.49 \%$ share), Computer Science (7.27\% share), etc. In terms of impact, Immunology and Microbiology registered the highest citation impact per paper (15.67) followed by Biochemistry, Genetics and Molecular Biology (11.67) and Neurosciences (11.24); and Computer Science the least (1.71) (Table 3).

\section{Top 20 Organisations}

A total of 847 organizations participated in research on this topic: 478 organizations contributing 1-5 papers each, 229 organizations 6-10 papers each, 106 organizations 11-20 papers each, 33 organizations 21-50 papers each, and 1 organization 63 papers.

The top 20 organizations individually published $24-63$ papers each and together published 18.65\% (644 papers) share and 39.70\% (13075 citations) share in global publications and citations. On further analysis, it was observed that; (i) Five organizations contributed papers above the group average (32.20) of 20 organizations: Harvard Medical School, U.S.A. (63 papers), All India Institute of Medical Sciences, New Delhi (48 papers), Moorfields Eye Hospital N.H.S. Foundation Trust, U.K. (47 papers), INSERM, France (35 papers) and Basecom Palmer Eye Institute, U.S.A. (33 papers); and (ii) Four organizations registered citation per paper and relative citation index (20.3 and 2.13) above the group average of 20 organizations: Tongji Medical College, China (126.59 and 13.27), Huazhong University of Science and Technology, China (103.09 and 10.81), National University of Singapore (23.27 and 2.44) and Harvard Medical School, U.S.A. (21.05 and 2.21)(Table 4).

\section{Top 20 Authors}

In all 2496 authors participated in research on this topic: 1545 authors contributed 1 paper each, 678 authors 2 papers each, 97 authors 3 papers each, 68 authors 4 papers each, 35 authors 5 papers each, 53 authors 6-10 papers each and 20 authors 11-20 papers each. 


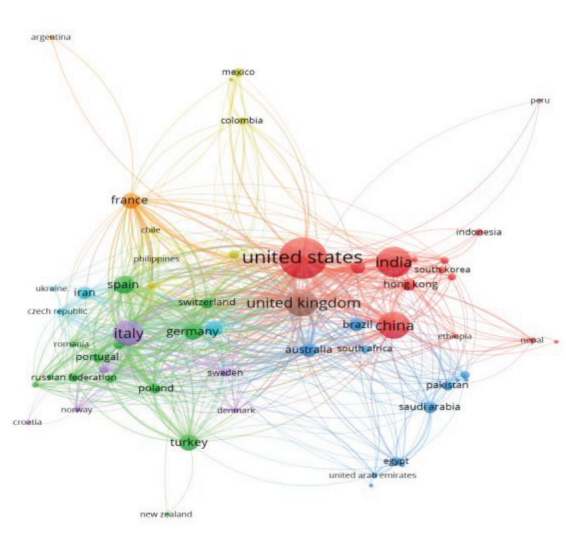

As vosviewer

Figure 1: Collaboration network by country.

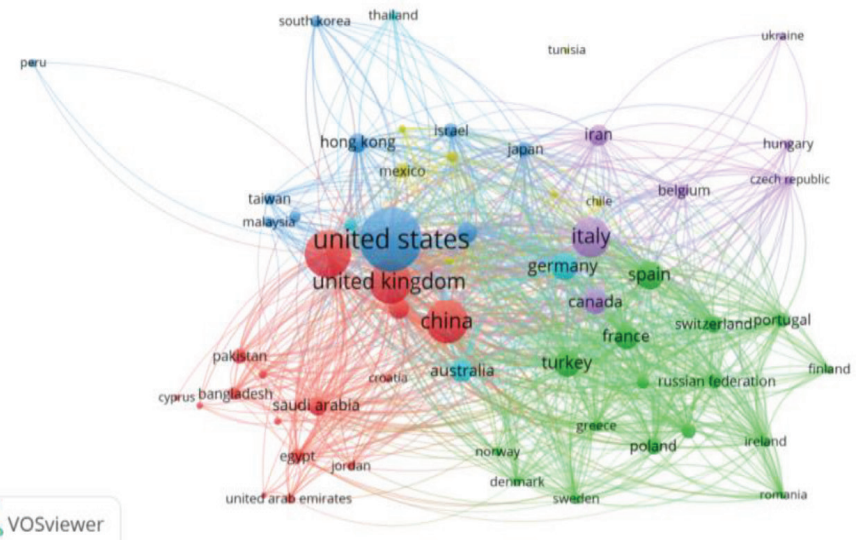

A vosviewer

Figure 2: Bibliographic coupling of Collaborative linakges.

Table 3: Subject-Wise Distribution of Papers.

\begin{tabular}{|c|c|c|c|c|c|}
\hline S.No & Name of the Subject & TP & TC & CPP & $\%$ TP \\
\hline 1 & Medicine & 2726 & 27541 & 10.10 & 78.95 \\
\hline 2 & Neurosciences & 293 & 3294 & 11.24 & 8.49 \\
\hline 3 & Computer Science & 251 & 430 & 1.71 & 7.27 \\
\hline 4 & Biochemistry, Genetics and Molecular Biology & 235 & 2733 & 11.63 & 6.81 \\
\hline 5 & Engineering & 189 & 797 & 4.22 & 5.47 \\
\hline 6 & Immunology and Microbiology & 175 & 2743 & 15.67 & 5.07 \\
\hline 7 & Environment Science & 148 & 1177 & 7.95 & 4.29 \\
\hline 8 & Social Sciences & 135 & 339 & 2.51 & 3.91 \\
\hline 9 & Pharmacology, Toxicology and Pharmaceutics & 115 & 695 & 6.04 & 3.33 \\
\hline \multirow[t]{2}{*}{10} & Health Professions & 87 & 496 & 5.70 & 2.52 \\
\hline & Global total & 3453 & 32935 & 9.54 & \\
\hline
\end{tabular}

TP - Total Publications, TC - Total Citations, CPP - Citations per Paper

Table 4: Bibliometric Profile of Top 20 Organizations.

\begin{tabular}{|c|c|c|c|c|c|c|c|c|}
\hline S.No & Name of the Organization & TP & TC & CPP & $\mathrm{HI}$ & ICP & \%ICP & $\mathrm{RCl}$ \\
\hline 1 & Harvard Medical School, USA & 63 & 1326 & 21.05 & 14 & 21 & 33.33 & 2.21 \\
\hline 2 & All India Institute of Medical Sciences, New Delhi, India & 48 & 252 & 5.25 & 8 & 2 & 4.17 & 0.55 \\
\hline 3 & Moorfields Eye Hospital NHS Foundation Trust, U.K. & 47 & 815 & 17.34 & 12 & 22 & 46.81 & 1.82 \\
\hline 4 & INSERM, France & 35 & 508 & 14.51 & 13 & 14 & 40.00 & 1.52 \\
\hline 5 & Basecom Palmer Eye Institute, USA & 33 & 166 & 5.03 & 8 & 5 & 15.15 & 0.53 \\
\hline 6 & University of Miami, Leonard M Miller School of Medicine, USA. & 32 & 203 & 6.34 & 8 & 5 & 15.63 & 0.66 \\
\hline 7 & Huazhong University of Science and Technology, China & 32 & 3299 & 103.09 & 12 & 10 & 31.25 & 10.81 \\
\hline 8 & Universita degli studi di Milano, Italy & 31 & 289 & 9.32 & 9 & 9 & 29.03 & 0.98 \\
\hline 9 & L.V.Prasad Eye Institute, Hyderabad, India & 30 & 266 & 8.87 & 9 & 6 & 20.00 & 0.93 \\
\hline 10 & Massachusetts Eye and Ear Infirmary, USA & 29 & 153 & 5.28 & 6 & 12 & 41.38 & 0.55 \\
\hline 11 & University of Toronto, Canada & 29 & 184 & 6.34 & 6 & 15 & 51.72 & 0.66 \\
\hline 12 & University of Health Sciences, Turkey & 29 & 191 & 6.59 & 6 & 2 & 6.90 & 0.69 \\
\hline 13 & Postgraduate Institute of Medical Sciences, Chandigarh, India & 27 & 288 & 10.67 & 9 & 7 & 25.93 & 1.12 \\
\hline 14 & Tongji Medical College, China & 27 & 3418 & 126.59 & 12 & 9 & 33.33 & 13.27 \\
\hline 15 & John Hopkins School of Medicine, USA. & 26 & 193 & 7.42 & 6 & 9 & 34.62 & 0.78 \\
\hline 16 & National University of Singapore & 26 & 605 & 23.27 & 9 & 17 & 65.38 & 2.44 \\
\hline 17 & Sapienza Universita di Roma, Italy & 26 & 253 & 9.73 & 8 & 4 & 15.38 & 1.02 \\
\hline 18 & University College London, U.K. & 25 & 354 & 14.16 & 9 & 12 & 48.00 & 1.48 \\
\hline 19 & University of Sydney, Australia & 25 & 216 & 8.64 & 9 & 20 & 80.00 & 0.91 \\
\hline \multirow[t]{4}{*}{20} & Aravind Eye Hospital, India & 24 & 96 & 4.00 & 5 & 4 & 16.67 & 0.42 \\
\hline & Total of 20 countries & 644 & 13075 & 20.30 & 8.9 & 205 & 32.73 & 2.13 \\
\hline & Global total & 3453 & 32935 & 9.54 & & & & 1.00 \\
\hline & Share of top organizations in global total & 18.65 & 39.70 & & & & & \\
\hline
\end{tabular}

TP - Total Publications, TC - Total Citations, CPP - Citations per Paper, HI - Hirsch Index, ICP - International Collaborative Publications. RCI - Relative citation impact 
The top 20 authors individually contributed 8 to 20 papers and together published 208 papers and received 1964 citations, constituting 6.02\% and $5.96 \%$ share in global publications and citations. On further analysis, it was observed that: (i) Five authors have contributed more than the group average of top 20 authors: A. Sharma (20 papers), R. Shetty (16 papers), R. Burgos-Blasco (15 papers), K.K.K. Li (13 papers) and N. Guemes - Villahoz 12 papers); (ii) Six authors registered citation per paper and relative citation index above group average (9.44 and 0.99) of 20 authors: R. Agarwal (39.6 and 4.15), K.K.K. Li (19.77 and 2.07), M. Sachdev (15.56 and 1.63), V. Gupta (13.63 and 1.43), F. Bandello (13.5 and 1.42) and A. Loewen Stein 13.25 and 1.39) (Table 5).

Figure 3 visualizes the co-authorship pattern of the authors. There are six clusters of authors that are formed in the visualization. The different colour represents the segregation of the authors. The red, blue and yellow clusters are inter-twined, showing that they have excellent collaboration among the authors.

\section{Source Distribution}

Among the 3453 papers, 3269 papers are published in journals, 144 in conference proceedings, 35 in book series, 4 in trade journals and 1 in book. The 3269 journal papers are published in 515 journals: 406 journals contributed 1-5 papers each, 63 journals 6-10 papers each, 30 journals 11-20 papers each, 14 journals 21-50 papers each and 2 journals 57-167 papers each.
Table 6 shows the top 20 journals individually contributed 19 to 167 papers and together published 762 papers, constituting $23.31 \%$ share of total papers in journals. The top 6 most productive journals are: Indian Journal of Ophthalmology (167 papers), Eye (Basingstoke) (57 papers), Graefe's Archive for Clinical and Experimental Ophthalmology (50 papers), JAMA Ophthalmology (44 papers), Clinical Ophthalmology (41 papers) and Ocular Immunology and Inflammation (37 papers). The top 6 most impactful journals in terms of citations per paper are: The Lancet (148.47), Journal of Medical Virology (42.0), Otolaryngology - Head and Neck Surgery (United States) (18.05), JAMA Ophthalmology (16.61), Ocular Immunology and Inflammation (16.03) and Journal of Clinical Medicine (13.08).

Figure 4 presents co-citation data on information sources. Every circle in the Figure represents a journal whose size represents the number of publications the journal has. The journals that are closely located to each other are related to each other in terms of co-citation. The Figure has segregated the sources into six clusters that are closely related.

\section{High-Cited Papers}

Of the 3453 papers, only 46 papers are high-cited papers and received 105 to 2585 citations. These 46 high-cited papers have received 13369 citations, registering citations per paper. Of the 46 high cited papers, 25 papers have received 105-195 citations, 3 papers 231-265 citations, 6 papers $511-887$ citations and 2 papers $1131-2585$ citations

Table 5: Bibliometric Profile of Top 20 Authors.

\begin{tabular}{|c|c|c|c|c|c|c|c|c|c|}
\hline S.No. & Name of the author & Affiliation of the author & T.P. & TC & CPP & $\mathrm{HI}$ & ICP & $\%$ ICP & $\mathrm{RCl}$ \\
\hline 1 & N. Sharma & AIIMS, New Delhi & 20 & 143 & 7.15 & 7 & 1 & 5.00 & 0.75 \\
\hline 2 & R. Shetty & Narayana Nethralaya, Bangalore & 16 & 119 & 7.44 & 6 & 1 & 6.25 & 0.78 \\
\hline 3 & R.Burgos-Blasco & Universidad Complutense de Madrid, Spain & 15 & 82 & 5.47 & 6 & 1 & 6.67 & 0.57 \\
\hline 4 & K.K.K. Li & United Christian Hospital, Hong Kong & 13 & 257 & 19.77 & 6 & 3 & 23.08 & 2.07 \\
\hline 5 & N. Guemes-Villahoz & Universidad Complutense de Madrid, Spain & 12 & 74 & 6.17 & 6 & 1 & 8.33 & 0.65 \\
\hline 6 & R. Agrawal & National Healthcare Group Eye Institute, Singapore & 10 & 396 & 39.6 & 6 & 10 & 100.00 & 4.15 \\
\hline 7 & S.C.L. Au & Tung Wah Eastern Hospital, Hong Kong & 10 & 13 & 1.3 & 2 & 0 & 0.00 & 0.14 \\
\hline 8 & F.Bandello & Universita Vita-Salute San Raffaele, Italy & 10 & 135 & 13.5 & 6 & 1 & 10.00 & 1.42 \\
\hline 9 & B.Gurnani & Aravind Eye Hospital, India & 10 & 20 & 2 & 3 & 1 & 10.00 & 0.21 \\
\hline 10 & K. Kaur & Aravind Eye Hospital, India & 10 & 20 & 2 & 3 & 1 & 10.00 & 0.21 \\
\hline 11 & S.Rizzo & Universita Catallolica del Sacrocuore, Campus di Roma, Italy & 9 & 85 & 9.44 & 5 & 2 & 22.22 & 0.99 \\
\hline 12 & M.Sachdev & AIIMS, New Delhi & 9 & 140 & 15.56 & 7 & 1 & 11.11 & 1.63 \\
\hline 13 & J.Garcia-Feijoo & Universidad Complutense de Madrid, Spain & 8 & 30 & 3.75 & 3 & 1 & 12.50 & 0.39 \\
\hline 14 & G.Glannaccare & Universita degli studi Catanzaro, Italy & 8 & 74 & 9.25 & 5 & 1 & 12.50 & 0.97 \\
\hline 15 & V.Gupta & PGIMER, Chandigarh & 8 & 109 & 13.63 & 6 & 7 & 87.50 & 1.43 \\
\hline 16 & A.Loewen Stein & Tel Aviv Sourrasky Medical Center, Israel & 8 & 106 & 13.25 & 4 & 6 & 75.00 & 1.39 \\
\hline 17 & S.Sanjay & Narayana Nethralaya, Bangalore & 8 & 8 & 1 & 2 & 1 & 12.50 & 0.10 \\
\hline 18 & M.C.Savastano & Universita Cattolica del SacroCuore, Campus di Roma, Italy & 8 & 70 & 8.75 & 4 & 2 & 25.00 & 0.92 \\
\hline 19 & R.Sinha & AIIMS, New Delhi & 8 & 47 & 5.88 & 6 & 1 & 12.50 & 0.62 \\
\hline \multirow[t]{4}{*}{20} & B.Vidal-Villagas & Universidad Complutense de Madrid, Spain & 8 & 36 & 4.5 & 3 & 1 & 12.50 & 0.47 \\
\hline & Total of 20 authors & & 208 & 1964 & 9.44 & 96 & 43 & 20.67 & 19.85 \\
\hline & Global total & & 3453 & 32935 & 9.54 & & & 0.00 & 1.00 \\
\hline & $\begin{array}{l}\text { Share of top } 20 \text { authors in } \\
\text { global total }\end{array}$ & & 6.02 & 5.96 & & & & 0.00 & 0.00 \\
\hline
\end{tabular}

TP - Total Publications, TC - Total Citations, CPP - Citations per Paper, HI - Hirsch Index, ICP - International Collaborative Publications, RCI - Relative citation impact 

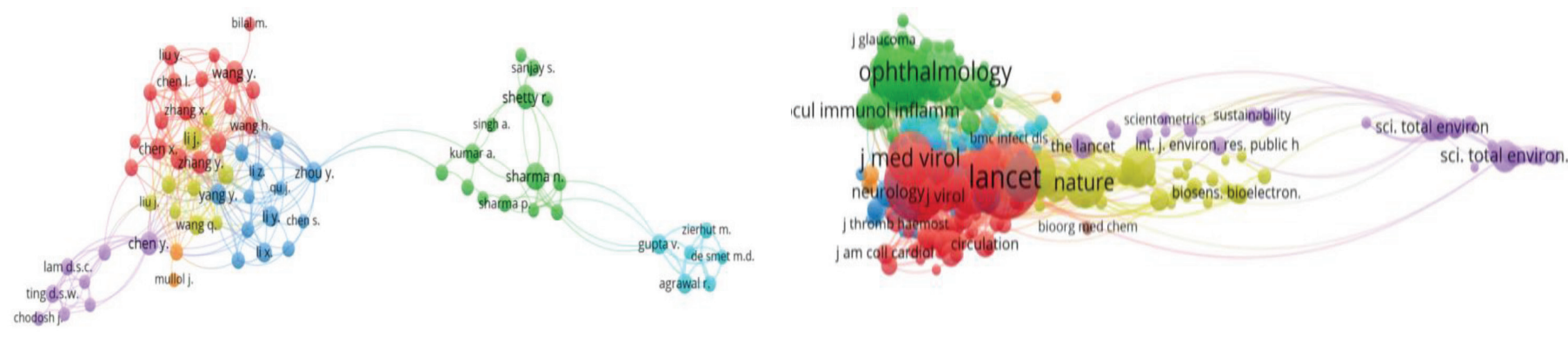

applied cognitive psychology

A. vosviewer

d. vosviewer

Figure 3: Co-authorship profile of top authors.

Figure 4: Co-citation network of sources.

Table 6: Bibliometric Profile of Top 20 Journals.

\begin{tabular}{|c|c|c|c|c|}
\hline S.No & Name of the journal & TP & TC & CPP \\
\hline 1 & Indian Journal of Ophthalmology & 167 & 909 & 5.44 \\
\hline 2 & Eye (Basingstoke) & 57 & 529 & 9.28 \\
\hline 4 & JAMA Ophthalmology & 44 & 731 & 16.61 \\
\hline 5 & Clinical Ophthalmology & 41 & 94 & 2.29 \\
\hline 8 & Journal of Medical Virology & 33 & 1386 & 42 \\
\hline 9 & Journal FrancaisD’ophtalmologie & 31 & 103 & 3.32 \\
\hline 10 & Ophthalmology & 30 & 385 & 12.83 \\
\hline 11 & European Journal of Ophthalmology & 30 & 124 & 4.13 \\
\hline 15 & Journal of Clinical Medicine & 24 & 314 & 13.08 \\
\hline 16 & Otolaryngology - Head And Neck Surgery (United States) & 21 & 379 & 18.05 \\
\hline 17 & Journal Of Glaucoma & 21 & 60 & 2.86 \\
\hline 18 & Canadian Journal Of Ophthalmology & 20 & 150 & 7.5 \\
\hline 19 & Journal Of Medical Internet Research & 19 & 33 & 1.74 \\
\hline \multirow[t]{4}{*}{20} & Lancet & 19 & 2821 & 148.47 \\
\hline & Total of 20 journals & 762 & 10006 & 13.13 \\
\hline & Global total & 3269 & & \\
\hline & Share of top 20 journals in global total & 23.31 & & \\
\hline
\end{tabular}

TP - Total Publications, TC - Total Citations, CPP - Citations per Paper

Among 46 high-cited papers, the U.S.A. contributed the largest number of papers (19), followed by China (14 papers), Singapore and U.K. (4 papers each), Italy and Hong Kong (3 papers each), Canada and France (2 papers each), Lebanon, Sweden, Brazil, Egypt, India, Iran, Malaysia, Greece, Spain and Philippines (1 paper each).

The 46 high-cited papers ( 27 articles, 9 letters, 6 reviews, 3 editorials and 1 note) have 10 non-collaborative papers and 36 involve 2 or more organizations (27 national collaborative and 9 international collaborative).
The 46 high-cited papers are published in 35 journals with 4 papers in the Lancet, 3 papers in Journal of Medical Virology, 2 papers each in JAMA, British Journal of Ophthalmology, Journal of Infection, New England Journal of Medicine and Nature Medicine and 1 paper each in 28 other journals.

\section{SUMMARY AND CONCLUSION}

The quest for quick responses to influence global policy has radically impacted the scientific community. In society, Covid-19 has affected 
rapidly in all aspects. These effects have been visible in the world of research publications, with a remarkable rise in Covid-19-related articles across a wide range of specializations. The authors looked at the implications of Covid-19 on ophthalmic publication patterns because of the present shifting landscape in medical literature and the lack of understanding about the impact of these changes on ophthalmology literature. A total of 3453 publications were retrieved from the Scopus database on "Ophthalmic Manifestations of Covid-19" from 2019-2022, and most of the document types are articles. Of the total publications, 557 are external funded which have received 10802 citations. The most important funded agency is the National Natural Science Foundation of China (98 papers). In this area, a total of 117 countries unevenly participated; the U.S.A. is the top country per the number of publications and citations received. India is in the second position as per the total number of publications (435) with 2553 citations. In terms of citation per paper, China leads in global rank.

The USA has maximum collaboration linkages ( 263 with 9 organizations) followed by UK (244 linkages wit 9 organizations) and Italy (162 linkages with 9 organizations). The USA, U.K. and India are seen as the most prominent countries in the collaboration network having most collaboration with other countries. The $78.95 \%$ share of total documents are from the 'Medicine' field, which contributed most of the research in "Ophthalmic Manifestations of Covid-19". A total of 847 organizations participated in this research on this topic, with Harvard Medical School, USA, contributing the largest number of publications. A total of 2496 authors participated in research on this topic, with $\mathrm{N}$. Sharma (AIIMS New Delhi) being the most productive author. In terms of the international collaborative publications, R. Agrawal (National Healthcare Group Eye Institute, Singapore) occupied the top rank. The source metrics total of 515 journals published research articles and Indian Journal of Ophthalmology is the most productive source. Out of 3453 papers, only 46 are high-cited papers and received 109 to 2629 citations published in 35 journals. The USA contributed the largest number of documents. Remarkably, all the documents were published in 2020, and all are in open access. This offers an insight into research on this topic and it is likely to help scholars who were researching in this field and policy-makers in identifying the potential areas of research on Covid-19 and Ophthalmology

\section{ACKNOWLEDGEMENT}

The authors acknowledge the support of the library and appreciate the Indian Institute of Technology (BHU.), Varanasi, for providing e-resources and materials used for this research.

\section{CONFLICT OF INTEREST}

The authors declare that there is no conflict of interest.

\section{REFERENCES}

1. Armstrong L, Collin J, Mostafa I, Queen R, Figueiredo FC, Lako M. In the eye of the storm: SARS-CoV-2 infection and replication at the ocular surface? Stem Cells TransI Med. 2021;10(7):976-86. doi: 10.1002/sctm.20-0543, PMID 33710758.

2. Hu K, Patel J, Swiston C, Patel BC. Ophthalmic manifestations of coronavirus (Covid-19). StatPearls [Internet]. 2021.

3. Vision impairment and blindness; n.d. [cited Sep 25 2021] Available from: https:// www.who.int/news-room/fact-sheets/detail/blindness-and-visual-impairment.

4. Seah I, Agrawal R. Can the coronavirus disease 2019 (COVID-19) affect the eyes? A review of coronaviruses and ocular implications in humans and animals. Ocul Immunol Inflamm. 2020;28(3):391-5. doi: 10.1080/09273948.2020.1738501, PMID 32175797.

5. Jevnikar K, Jaki Mekjavic P, Vidovic Valentincic N, Petrovski G, Globocnik Petrovic M. An update on Covid-19 related ophthalmic manifestations. Ocul Immunol Inflam. 2021:1-6.

6. Kalra G, Kaur R, Ichhpujani P, Chahal R, Kumar S. Covid-19 and ophthalmology: A scientometric analysis. Indian J Ophthalmol. 2021;69(5):1234-40. doi: 10.4103/ ijo.IJO_3284_20, PMID 33913867.

7. Jin YP, Trope GE, El-Defrawy S, Liu EY, Buys YM. Ophthalmology-focused publications and findings on Covid-19: A systematic review. Eur J Ophthalmol. 2021;31(4):1677-87. doi: 10.1177/1120672121992949, PMID 33557602.

8. Reitinger J, Jain SF, Suh D. Significant increase in non-Covid-19 related ophthalmology publications during the COVID-19 era: is this a new normal? Eye (Lond). 2021;35(4):1041-2. doi: 10.1038/s41433-020-01220-3, PMID 33051622

9. Sen M, Honavar SG, Sharma N, Sachdev MS. Covid-19 and eye: a review of ophthalmic manifestations of Covid-19. Indian J Ophthalmol. 2021;69(3):488-509. doi: 10.4103/ijo.IJO_297_21, PMID 33595463.

10. Bibliometric database Scopus. Available from: https://www.scopus.com/ search/form.uri? [accessed on Sep 20 2021].

11. Dervis $H$. Bibliometric analysis using bibliometrix an $R$ package. JSCIRES 2020;8(3):156-60. doi: 10.5530/jscires.8.3.32. 